\title{
JANE AUSTEN E O FENÔMENO DA AUTORIA-ZUMBI EM PRIDE AND PREJUDICE AND ZOMBIES
}

\author{
Ivoneide Soares dos Santos de Jesus \\ Universidade Federal de Mato Grosso \\ Vinícius Carvalho Pereira ${ }^{* *}$ \\ Universidade Federal de Mato Grosso
}

\begin{abstract}
Resumo
Pride and Prejudice and Zombies, de Jane Austen e Seth Grahame-Smith, é um mashup literário, procedimento de fragmentação de uma obra clássica para nela enxertar elementos da cultura pop contemporânea. Um dos principais questionamentos levantados pelo romance envolve o jogo de palimpsesto inerente à sua autoria, uma vez que a obra foi produzida através da escrita de uma autora morta (Austen) e de um autor vivo (Grahame-Smith). Cabe notar que a romancista inglesa do período regencial já experimentara intricadas dinâmicas para atribuição de autoria às suas próprias obras quando de sua publicação pela primeira vez. Nesse contexto, o presente artigo analisa o jogo entre autor vivo/letra morta e obra viva/escritor morto, tão marcante na colaboração artística que gerou Pride and Prejudice and Zombies.
\end{abstract}

Palavras-chave: Mashup literário; Autoria-zumbi; Jane Austen.

\section{JANE AUSTEN AND THE ZOMBIE AUTHORSHIP PHENOMENON IN PRIDE AND PREJUDICE AND ZOMBIES}

\begin{abstract}
Pride and Prejudice and Zombies, by Jane Austen and Seth Grahame-Smith, is a literary mashup, a fragmentation procedure of a classical work so as to engraft into it elements from contemporary pop culture. One of the main questions raised by the novel involves the palimpsest game inherent to its authorship, since the work was produced through the writings of a dead author (Austen) and a living author (Grahame-Smith). The English novelist from the regency period had already experienced intricate dynamics of authorship attribution to her own works when they were published for the first time. In this context, we herein analyze the dialectics between a living author/dead letter and a living work/dead writer, so important in the artistic collaboration that generated Pride and Prejudice and Zombies.
\end{abstract}

Keywords: Literary mashup; Zombie authorship; Jane Austen.

\footnotetext{
Mestra em Estudos de Linguagem pela Universidade Federal de Mato Grosso. Licenciada em Letras/Inglês, também pela UFMT (2013). Membro do grupo de pesquisa Semióticas Contemporâneas (SEMIC/UFMT)

** Doutor em Ciência da Literatura pela UFRJ. Professor do Departamento de Letras e do Programa de PósGraduação em Estudos da Linguagem na UFMT.
} 


\section{Introdução}

No fim da primeira década do século XXI, lançou-se no mercado editorial uma nova gama de produções literárias cuja forma e conteúdo chamaram a atenção dos leitores ávidos por novidades e também de parte da crítica literária: os mashup literários, que são "textos compostos pela combinação de vários outros textos" (SCHNEIDER, 2009, p.iv, tradução nossa). ${ }^{1}$ Em linhas gerais, trata-se de adaptações de obras canônicas em que figuram elementos da cultura pop contemporânea, inseridos, quando da adaptação, junto a grandes porções do texto original. Outra definição apresenta o mashup literário como um tipo de ficção produzido a partir da combinação de gêneros totalmente diferentes para formar uma nova narrativa, essencialmente híbrida, a qual, apesar de se configurar como algo novo, apresenta rastros das que lhe deram origem (MURPHY, 2013, n.p).

Publicado pela primeira vez nos Estados Unidos em 2009, Pride and Prejudice and Zombies foi o precursor de vários outros mashups literários. Em sua contracapa, Pride and Prejudice and Zombies é apresentado como uma "uma edição expandida do romance mais amado de Jane Austen com cenas de zumbis mutilando ossos" (AUSTEN; GRAHAME-SMITH, 2009, n.p., tradução nossa). ${ }^{2}$ $\mathrm{Na}$ obra, o calmo vilarejo de Meryton foi acometido por uma misteriosa praga que vem levantando os mortos de suas tumbas, devolvendo-lhes em parte a vida. A heroína do romance, Elizabeth Bennet, treinada nas artes marciais chinesas, juntamente às suas irmãs, é encarregada pelos governantes ingleses de proteger o local onde vivem. Elizabeth está determinada a dar um fim à ameaça zumbi, porém é distraída pela chegada do altivo e arrogante Sr. Darcy. Ainda na descrição da contracapa, o romance é descrito como uma "deliciosa comédia de costumes com uma disputa civilizada entre os dois amantes - e disputas ainda mais violentas, com um campo de batalha encharcado de sangue" (AUSTEN; GRAHAME-SMITH, 2009, n.p., tradução nossa). ${ }^{3}$

Na capa do livro, leem-se justapostos os nomes dos autores a quem se atribui tal obra: Jane Austen e Seth Grahame-Smith, isto é, uma escritora inglesa nascida no século XVIII e um escritor norte-americano ainda vivo. O estranhamento acarretado por essa atribuição de autoria se deve a uma série de causas, entre as quais se incluem: a "pilhagem" do texto austeniano; o uso do nome da escritora inglesa como chancela para uma obra que ela só em parte conhecera; e um suposto trabalho colaborativo entre sujeitos que jamais se encontraram para a produção de um texto que só um dos dois veria escrito.

Na medida em que conta uma história sobre uma invasão de mortos-vivos, escrita por uma autora morta e um vivo, este romance pode ser tomado, então, como precursor de uma instância autoral morta-viva (JESUS; PEREIRA, 2015), que nos parece ser uma das características dos romances mashup. Diante desse cenário, tomamos neste artigo a figura do zumbi como um elemento metaforizador do processo autoral nos romances mashup, a fim de analisar Pride and Prejudice and Zombies enquanto texto construído por meio de fragmentos extirpados ao canônico Pride and Prejudice e enxertos da cultura pop, atualmente tomada 
pela temática do apocalipse e dos zumbis. Recombinados, tais elementos formam na obra de Austen e Grahame-Smith um corpo (textual) zumbificado, que justifica a nomenclatura que aqui lhe damos: obra-zumbi.

Cabe ainda notar que a romancista inglesa do período regencial já experimentara intricadas dinâmicas para atribuição de autoria às suas próprias obras quando de sua publicação pela primeira vez. O jogo entre autor vivo/letra morta e obra viva/escritor morto é parte constituinte da tríade publicação-circulação-recepção dos romances austenianos; logo, o que Pride and Prejudice and Zombies faz, instalando uma autoria morta-viva híbrida entre Austen e Grahame-Smith, pode ser visto como uma potencialização de fenômenos editoriais e autorais já existentes no século XVIII, como este artigo visa analisar.

Para tanto, partimos da metáfora do zumbi, investigando o rendimento literário desse monstro em diferentes tempos e épocas, a fim de melhor entendermos essa imagem que nos servirá de baliza para, na seção seguinte, indagar como a autoria zumbi perpassa a textualidade austeniana desde seus primeiros romances até o mashup a que seu nome é atribuído como coautora no século XXI. Ademais, analisa-se aqui em que medida diferentes tecnologias da escrita influenciaram os processos de zumbificação dos textos que carregam o nome da escritora britânica como chancela de autoria.

\section{Zumbi: o monstro que se mostra}

Monstro ambivalente, o zumbi que conhecemos hoje veio ao mundo literário a partir de A Ilha da Magia, de William Seabrook, obra lançada nos Estados Unidos em 1929. Viajante experiente, Seabrook tinha conhecimento sobre a lenda caribenha dos mortos ambulantes. Tendo a noção de que outro pesquisador, o jornalista e antropólogo Lafcadio Hearn, não progredira muito em sua pesquisa sobre os mortos-vivos no século XIX, Seabrook parte para o Caribe e se instala no Haiti, local onde a lenda era mais difundida (RUSSELL, 2010). É Seabrook quem definitivamente muda o status do zumbi, de lenda haitiana a mito urbano, símbolo do caos. Assim, a criatura inicia sua caminhada no imaginário contemporâneo a partir da década de 30 , o que faz desse um dos monstros mais recentes dentro do gênero horror.

Um ponto interessante sobre a trajetória de Seabrook é que ele só escrevia sobre aquilo que vivenciava (RUSSELL, 2010). Em seus relatos sempre há um tom de verdade atribuído às histórias que ouvia ao longo de suas viagens, o que demonstra desde o início que a lenda do zumbi caribenho foi trazida ao mundo ocidental sob um aparato discursivo de suposta veracidade.

Seabrook viajou pelo Haiti colhendo histórias sobre os mortos-vivos, nas quais o zumbi invariavelmente figurava como um símbolo de desgraça, medo e perdição. Após massiva coleta de dados, o pesquisador descobriu que o ponto central da história sobre os zumbis estava na religião dos nativos do Haiti, o vodu. Assim como no cristianismo, no vodu alma e corpo são entidades distintas, que podem existir separadamente. 
Segundo Seabrook, alguns feiticeiros retiravam a alma de pessoas para torná-las escravas no regime de plantation. O procedimento místico se iniciava pela intoxicação das vítimas com uma substância que as fazia entrar em estado de letargia. Procedia-se ao enterro dos corpos inertes e, mais tarde, os feiticeiros reviviam-nos por meio de magia negra que revertia o processo anterior. Entretanto, os mortos, ao "ressuscitarem", perdiam suas almas (e, portanto, suas identidades), tornando-se corps cadavres, ou "mortos que caminham" (RUSSELL, 2010). Os corpos sem alma, tornados zumbis, eram então enviados como escravos para trabalhar nas fazendas de açúcar do Haiti.

A história dos corpos que caminham sem espírito se espalhou pela ilha e tornou-se parte do senso comum, aterrorizando o povo haitiano, o qual passou a dedicar mais tempo a cuidar de seus mortos, com medo de eles virem a se transformar em zumbis. Havia situações em que se tentava "matar novamente" os cadáveres, com tiros ou injeção de veneno, para impedir que fossem roubados pelos ladrões de túmulo - que a essa altura ganhavam muito ao pilhar corpos e entregá-los aos feiticeiros vodus. Como descrito em A Ilha da Magia, o zumbi era "um cadáver sem alma, ainda morto, mas tirado do túmulo e mantido sob feitiçaria com um semblante mecânico de vida - é um corpo que se faz andar e agir como se estivesse vivo" (SEABROOK apud RUSSELL, 2010, p.28).

Apesar da recusa de Seabrook a acreditar nos zumbis, no Código Penal do Haiti há um parágrafo específico ( $\left.n^{\circ} 249\right)$ que trata dos problemas referentes à lenda dos mortos-vivos, no qual se pode ler que

é considerado atentado à vida de uma pessoa o emprego feito contra ela de substâncias que, sem produzir morte, causam o efeito letárgico mais ou menos prolongado, quaisquer que sejam as consequências. Se por efeito desse estado letárgico a pessoa for enterrada, o atentado será considerado assassinato (RUSSELL, 2010, p.31).

Assim, apesar de ver e não crer, Seabrook abriu as "portas infernais do imaginário humano" para que os mortos-vivos vagassem eternamente entre nós.

No final do século XVIII, escravos do sul dos Estados Unidos já contavam histórias sobre esse monstro. Entretanto, apenas no século seguinte a narrativa sobre zumbis começaria a assombrar o imaginário do homem moderno, com a aparição do termo no livro History of Brazil, uma coletânea publicada em três volumes na Inglaterra entre 1810 e 1819, de Robert Southey (RUSSELL, 2010). Em um dos episódios, Southey narra uma revolta de escravos contra os senhores de engenho, liderada por um homem identificado apenas como Zombi, nome dado em homenagem a um deus angolano.

Monstro híbrido, o zumbi entrelaça diferentes culturas, contextos, povos e línguas. Este cruzamento intercultural pode ser visto a partir da etimologia da palavra "zumbi”. Há divergências linguísticas quanto à origem do nome desse monstro, que pode ter vindo do francês ombres (sombra), do caribenho jumbie (fantasma), do kongo nzambi (espírito morto), ou de zemis, um termo vindo da tribo indígena Arawak do Haiti, usado para descrever a alma de um morto (RUSSELL, 2010). 
Na trajetória histórica da construção desse mito moderno, a lenda do zumbi se espalhou pelo mundo, atingindo os países da América Central. Em 1819, o termo seria registrado no Oxford English Dictionary, ratificando a penetração no mundo anglófono dessa criatura mítica, que então já detinha o status de monstro, segundo a acepção do mundo ocidental.

O zumbi inicialmente descrito por Seabrook logo faria parte do imaginário americano e, por conseguinte, mundial. No mesmo ano de lançamento de A Iha da Magia, os Estados Unidos mergulhariam na Grande Depressão, ocasionada pela quebra da bolsa de valores de Nova York em 24 de outubro de 1929; a ascensão do mito do zumbi acompanhou, pois, o mergulho do país no caos. Ao longo das duas décadas seguintes, o horror habitaria tanto as ruas quanto as livrarias, os cinemas e os teatros. O zumbi corporificou o sofrimento do povo impotente perante uma crise que deixou grandes empresários em condições miseráveis: "o zumbi - um trabalhador morto ressuscitado como um escravo em uma infernal vida após a morte de trabalho sem fim - era o monstro perfeito para a época" (RUSSELL, 2010, p.46).

O primeiro filme com zumbis, que pode ser considerado como o que alçou o monstro à condição de mito contemporâneo nos mass media, é White Zombie, dirigido por Victor Halperin e lançado em 1932, no auge da Grande Depressão. O filme sugere uma leitura do povo americano massificado, sem identidade, em uma prévia do que seria a mais comum crítica ao sujeito pós-moderno.

Apenas em 1968, quando George Romero lança o filme A noite dos mortos-vivos, a imagem do zumbi foi desatada do vodu haitiano (GOMES, 2013), tornando-se como é conhecida no século XXI, na TV, no cinema ou nas obras literárias: o homem transformado em monstro por outros meios, da doença à queda de objetos voadores não identificados, mas não mais a feitiçaria. Essa ausência da razão à qual o sujeito contemporâneo vem sendo submetido, seja pela alienação da mídia, pelo uso de drogas, ou mesmo por doenças, vai desaguar na perda da identidade: o zumbi não tem nome, nem endereço. Um sujeito sem lar, sem vida, sem direito a nada. Isso justifica o fato de o mito sobre o zumbi ter sido construído como o de um monstro que devora carne humana, sendo seu prato preferido o cérebro.

O zumbi causa terror ao homem não só porque metaforiza o caos das sociedades contemporâneas, mas também porque ele é um outro eu humano, um alter ego. Representa o lado do homem que, sem querer, pode produzir seu fim. Esse monstro trouxe consigo o imaginário do apocalipse zumbi, no qual o mundo terminaria com todo ser humano se tornando um monstro desse tipo: ameaça da dessubjetivação de toda a sociedade de consumo.

É, pois, como elemento da cultura pop, com conotação de dessubjetivação e massificação, que o zumbi é mobilizado no plano do conteúdo e da expressão no romance mashup Pride and Prejudice and Zombies. Ao ser questionado em uma entrevista sobre como foi o processo de construção da obra, Seth Grahame-Smith explicou que o trabalho de "escrita" aconteceu em duas etapas, em que se nota claramente uma tensão dialética entre repetição e alteridade, corte e enxerto, vida e morte: uma zumbificação textual, portanto. 
Na primeira etapa do processo de composição, Seth Grahame-Smith se dedicou à leitura de Pride and Prejudice, realçando na cor vermelha as passagens que poderiam ser extirpadas para inserir os enxertos com zumbis. No segundo momento, colou em seu computador um arquivo contendo o texto-fonte e procedeu à subtração definitiva dos trechos de Austen para inserção dos enxertos contendo os zumbis. Periodicamente, ele verificava a dosagem entre sua escrita e a de Austen (KELLOGG, 2009), procurando, assim, manter mais trechos austenianos que os seus.

Nota-se que, na visão do próprio Seth Grahame-Smith, "escrever" Pride and Prejudice and Zombies foi como efetuar uma espécie microcirurgia em Pride and Prejudice (TAKAHASHI, 2011), em que, para produzir um romance de massa - monstro massificado como o zumbi -, os limites entre a escrita de Austen e Grahame-Smith se perdem. Criando-se uma zona de indeterminação entre esses textos, dão eles lugar a uma indiferenciada massa textual que, como os monstros de A Ilha da Magia, vem marcada por uma dessubjetivação já à primeira vista.

Assim, a horda de zumbis que invade o condado de Meryton no enredo adaptado do romance mashup acaba por metaforizar o modo como, no plano da enunciação, Seth Grahame-Smith invadiu o livro de Austen, apropriando-se da escrita alheia. $\mathrm{O}$ autor, qual um zumbi, morde trechos, corta diálogos e mata personagens criados pela escritora inglesa, abrindo espaço para novos movimentos na narrativa e novas compreensões da dinâmica autoral, conforme se analisa em mais detalhes na próxima seção.

\section{Jane Austen: uma autora-zumbi?}

Em "A morte do autor", Roland Barthes discorre acerca da figura autoral, afirmando a dificuldade que se tem para encontrar a voz por trás do texto, pois "a escrita é a destruição de toda voz, de toda origem" (BARTHES, 2004, p.1). Segundo tal paradigma, seria a linguagem que fala por si, não um sujeito empírico produtor do discurso. A língua, como um sistema de signos, impossibilitaria uma verdadeira criação $a b$ nihilo, uma vez que todo texto apenas manipularia os signos e a sintaxe definidos a priori pelas regras do sistema, segundo a célebre ideia de "fascismo da língua" (BARTHES, 1992).

$\mathrm{Na}$ lógica barthesiana, a escrita da narrativa é feita por um "corpo que escreve", por um "mediador"; ou seja, o suposto autor seria, na verdade, uma ferramenta a serviço da linguagem. Revisitam-se, então, os pressupostos sobre autoria anteriores à Idade Média, na medida em que o autor seria uma figura fictícia inventada pela modernidade, que descobriu o prestígio pessoal do indivíduo, da pessoa humana.

Para Barthes (2004, p.4), "dar um autor ao texto é impor a esse texto um mecanismo, é dotá-lo de um significado último, é fechar a escrita”. Nesse sentido, afirmar que um texto pertence a determinado autor implicaria que tal texto devesse ser analisado em busca da intenção autoral, fortemente condicionada pela biografia do sujeito empírico, o que foi reiteradamente rechaçado por Barthes 
em seus textos. Para esse teórico francês, matar o autor seria necessário, a fim de olhar apenas para imanência textual no ato da crítica, interpretando apenas o que se pode ver no texto como letra-morta.

Sob tal perspectiva, Pride and Prejudice ter-se-ia desligado de Jane Austen ao ser colocado no papel. Esse apagamento da autora, por meio das operações algorítmicas da língua, transformaria o que era livro fechado em obra aberta, passível de mil e uma interpretações (ECO, 1991). A enunciação de um Autor-Deus desapareceria, assim, para dar lugar a um espaço textual onde se encontram inúmeras escritas, vindas de múltiplas fontes que se casam e se contestam, mas que perdem o contato com a matriz, tendo em vista que, ao contar uma história, ela se desliga do contador. Somente nessa dinâmica de abertura para a leitura, desencadeada pela morte do autor, pode-se entender Pride and Prejudice and Zombies como um espaço textual em que autora morta e autor vivo se encontram para produzir um texto morto-vivo - obra zumbi que este artigo analisa.

Jane Austen publicou Pride and Prejudice em 1813, enquanto Pride and Prejudice and Zombies foi publicado pela primeira vez em abril de 2009. No romance mashup, Austen se torna uma autora-zumbi porque, em alguma medida, ressuscita na coautoria com um escritor vivo, ressurgindo da tumba quase dois séculos depois para presenciar novamente a publicação de sua obra-prima, mas agora zumbificada.

Sabe-se que Jane Austen é, atualmente, consagrada como uma das figuras femininas mais importantes no cenário literário inglês. $\mathrm{O}$ que não se comenta muito é que a escritora inglesa morreu no anonimato, no século XIX, sem figurar nominalmente como autora de seus romances nas edições publicadas em vida. Logo, pode-se dizer que a escritora fora autora-zumbi, isto é, sem identidade declarada, já em seus próprios textos.

Austen-Leigh $^{4}$ (2014), sobrinho da escritora, argumenta que o processo de publicação dos romances de sua tia ocorreu da seguinte forma: o primeiro a ser lançado foi Sense and Sensibility (1811); depois, vieram Pride and Prejudice (1813), Mansfield Park (1814), Emma (publicado em dezembro de 1815, porém consta indevidamente como ano de publicação 1816), Persuasion e Northanger Abbey (publicados postumamente em 1817, mas consta em suas capas 1818 como ano de publicação). A seguir, a fim de melhor entendermos a intrincada dinâmica entre autoria ausente e presente, morta e viva, humana e zumbi, nos romances de Austen, procede-se a uma análise das folhas de rosto dessas obras.

Em primeiro lugar, uma análise da folha de rosto da primeira versão de Sense and Sensibility (ainda intitulado Sense and Sensibility: a novel, como se vê na Figura 1) revela que, nesse elemento pré-textual, não consta uma assinatura autoral de Austen, apenas referida como "a lady", ocultando-se seu nome próprio, isto é, aquilo que dá a um sujeito o direito à identidade. Desidentificada, a autora ganha traços de dessubjetivação como os dos zumbis descritos por Seabrook, os quais são alienados de si, tal qual a escritora que se vê alienada de sua voz autoral por um sistema que invisibilizava a mulher. $\mathrm{O}$ nome próprio, identidade que dá a um sujeito o direito não apenas de pertencer a um lugar, mas também de que algo lhe pertença, foi negado a Austen na capa de seu romance, como se nota na imagem abaixo. 


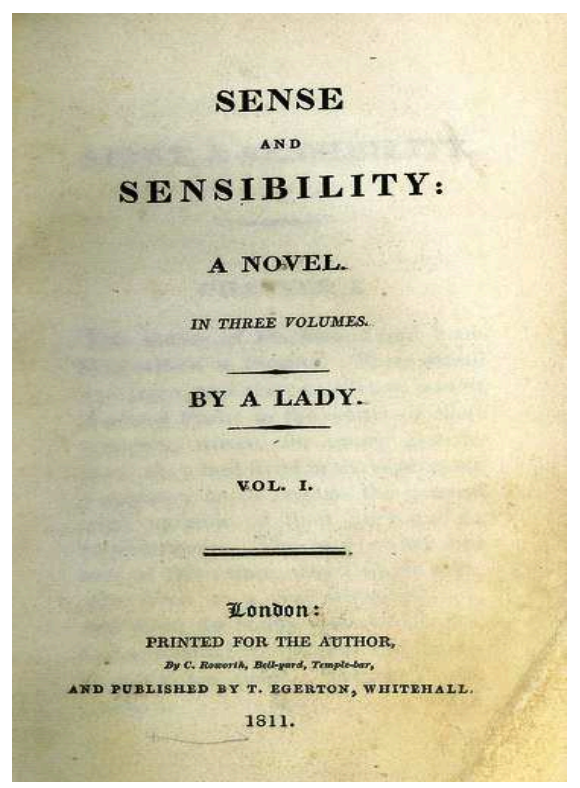

Figura 1. Folha de rosto da primeira edição de Sense and Sensibility (1811). Fonte: https:// smithandgosling.wordpress.com/tag/sense-and-sensibility/. Acesso em 20 jul 2015.

A folha de rosto de Sense and Sensiblity indica que o romance foi impresso pelx autorx, ${ }^{5} \mathrm{em}$ vez de aí figurar o nome de Jane Austen, a qual pagou para que a obra fosse publicada por Thomas Egerton. Entretanto, no lugar do nome de Austen, está o substantivo neutro author, que oculta não só o nome da escritora, mas mesmo seu gênero, o qual estaria, por outro lado, expresso na expressão "by a lady".

Na publicação do romance seguinte, Pride and Prejudice (no original, Pride and Prejudice: a novel, ${ }^{6}$ conforme Figura 2), observa-se que se complexifica a questão da autoria, pois oculta-se um novo dado do autor empírico: seu gênero. Ao não colocar o nome do autor na capa do romance, nem adicionar uma expressão com marcação de gênero em inglês, o editor de Pride and Prejudice deixava indefinido se o autor da obra era de fato um sujeito do sexo feminino ou masculino, intensificando o jogo de ausência e presença de Jane Austen em seu livro. Sem nome, sem personalidade, sem gênero, é já como zumbi, pois, que Austen comparece como autora nesta obra. 


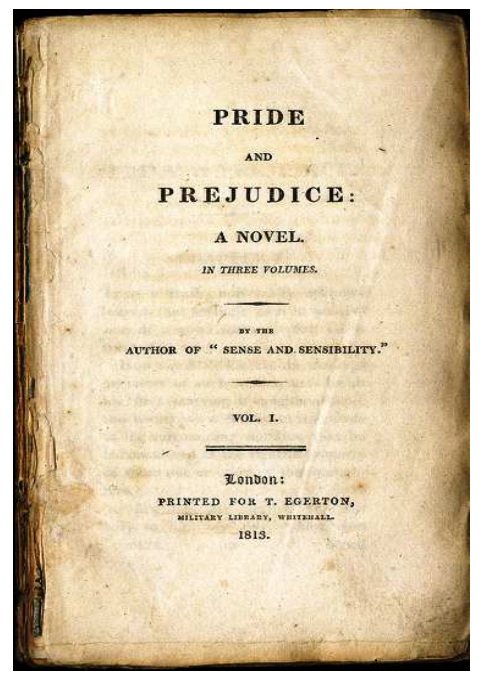

Figura 2. Folha de rosto da primeira edição de Pride and Prejudice (1813). Fonte: https:// janeausteninvermont.wordpress.com/2009/01/28/january-28-1813-pride-prejudicepublished/. Acesso em 03 dez 2013.

$\mathrm{Na}$ folha de rosto dessa edição, nota-se que, em vez de "by a lady", indicando o gênero da autora, tudo o que se tem a respeito da autoria é a expressão "by the author of Sense and Sensibility". ${ }^{7}$ Desse modo, o romance anuncia sua autoria como derivada de Sense and Sensibility, o qual, por sua vez, informava apenas que sua anônima autora era do sexo feminino.

Assim, se no século XIX houvesse conferências para lançamentos de livros com a presença do autor, a cadeira de Jane Austen certamente estaria vazia; ou, se seus fãs oitocentistas quisessem um autógrafo em uma edição de Pride and Prejudice, por exemplo, não poderiam obtê-lo, pelo fato de o romance ter sido creditado a um autor sem identidade. Afinal, em Pride and Prejudice, Jane Austen perde o status enquanto sujeito cujas mãos deitaram o texto no papel; em uma sociedade chauvinista como a da Inglaterra do século XIX, escrever não era uma atividade tão digna para um sujeito feminino quanto cuidar de uma casa. Esse poderia ter sido um dos motivos que levaram a autora a ausentar-se enquanto nome ou assinatura autoral na folha de rosto de seus romances, confirmando a dinâmica de presença ausente cara a todo zumbi.

Sua família, mais tarde, tentou apresentar uma nova explicação para esse fato, afirmando que Austen gostava de ter uma vida interiorana e pacata, evitando ser vista durante seu ofício. Segundo seu sobrinho James Edward Austen-Leigh (2014), a escrita de Austen era uma atividade que apenas a família conhecia.

[Jane Austen] cuidava para que sua ocupação não fosse suspeita pela criadagem, visitantes ou qualquer pessoa além de sua família. Escrevia em pequenas folhas de papel que poderiam facilmente ser escondidas ou cobertas com um pedaço de mata-borrão (AUSTEN-LEIGH, 2014, p. 106).

Austen conseguiu ao longo de sua vida manter-se longe da fama e, apesar de no final de sua vida já gozar de um público leitor considerável, morreu sem ser 
consagrada como autora das próprias obras. Na nota biográfica presente na publicação póstuma de seus dois últimos romances, seu irmão Henry James Austen faz a seguinte afirmação ao falar sobre os dotes artísticos da autora:

Sua voz era extremamente doce. Ela se expressava com fluência e precisão. De fato, ela foi formada para uma sociedade elegante e racional, destacando-se tanto na conversação quanto na composição. Na época atual, é perigoso mencionar tais feitos ${ }^{8}$ (MORLAND’S, 2015, n.p., tradução nossa).

Quando da publicação da obra seguinte, a primeira edição de Northanger Abbey e Persuasion, Austen já estava morta. Note-se, nesse caso, que, embora tenham sido publicados em dezembro de 1817, os romances têm como ano de publicação 1818, conforme se vê na Figura 3.

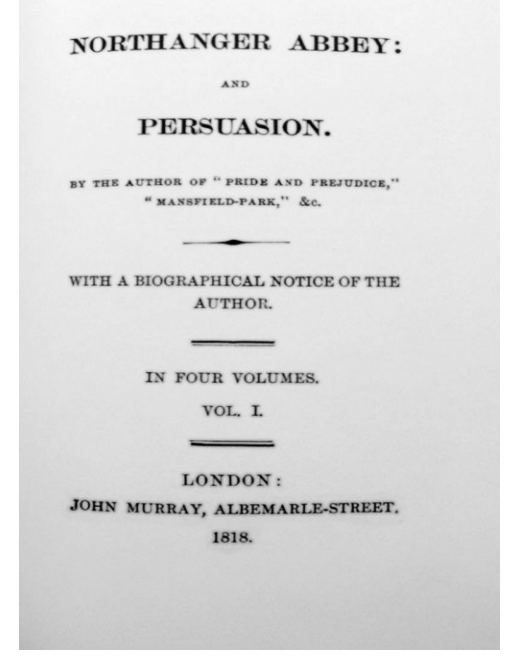

Figura 3. Folha de rosto da primeira edição de Northanger Abbey e Persuasion (1818). Fonte: http://www.aucklandcity.govt.nz/dbtw-wpd/virt-exhib/Romantics/case10.htm. Acesso em 03 jul 2014.

A autoria de Northanger Abbey e Persuasion é expressa na legenda "by the author of Pride and Prejudice and Mansfield Park \&c". Em dezembro de 1817, Jane Austen já havia falecido, de modo que seu irmão Henry Austen intermediava as negociações com as editoras, tendo inclusive escrito uma nota biográfica para a publicação póstuma dos dois romances, como se percebe na Figura 3. A seguir, transcreve-se o primeiro parágrafo da referida nota:

As páginas seguintes são a produção de uma pena que já contribuiu em grande medida para o entretenimento do público. E quando o público, que não tem sido insensível aos méritos de "Razão e Sensibilidade", "Orgulho e Preconceito", "Mansfield Park", e "Emma", for informado que a mão que guiou aquela pena está agora se decompondo no túmulo, talvez um breve relato sobre Jane Austen seja lido com um sentimento mais amável do que simples curiosidade (MORLAND'S, 2015, n.p., tradução nossa)..$^{10}$ 
Henry Austen afirma aí que os romances apresentados nas páginas seguintes haviam saído da caneta de pena de alguém que já havia contribuído em grande escala para o entretenimento do público, o que pode ser lido como indício de que os romances de Jane Austen tinham valor de literatura de massa à época. Ademais, é nessa nota biográfica que, pela primeira vez, o nome de Jane Austen é claramente associado à autoria dos textos, ainda que cinco meses após a morte da escritora.

Ainda na mesma nota, Henry Austen se refere à irmã usando uma terminologia datada, marcada por um sufixo indicativo do gênero feminino: authoress: "Our authoress would, probably, have been inferior to few in such acquirements, had she not been so superior to most in higher things" (MORLAND'S, 2015, n.p). ${ }^{11}$

No século XX, o papel da mulher começou a mudar na sociedade inglesa e o movimento feminista passou a observar como sexismo e paternalismo o uso do sufixo - ess para profissionais mulheres em termos como editress e poetess, que caíram em desuso, tal qual authoress. Por outro lado, no século XIX, o uso desse termo ainda prevalecia, como se observa na nota biográfica. Isso ratifica que a escolha da assinatura autoral como "by an author", nas primeiras edições de seus romances, de fato implicava um apagamento do gênero da escritora, e a mantinha em uma ambivalente situação de presença e ausência enquanto autora de seus livros.

Não colocado seu nome na capa de seus romances, a Jane Austen foi negado o direito de pertencimento de suas obras, de modo que a autora se tornasse também uma não mencionável, tal como são chamados os zumbis em Pride and Prejudice and Zombies, pois aquelas criaturas habitavam o espaço da vida e da morte mas não tinham o direito a um discurso.

No prefácio de uma edição brasileira do romance Persuasão (AUSTEN, 2011), para a editora L\&PM, o tradutor e poeta Ivo Barroso afirma que a família de Austen, principalmente seu irmão Henry, desejou que em vida ela fosse reconhecida como autora de seus romances, porém "a modéstia da irmã (ou as inconveniências sociais da época) só permitiram que essa revelação fosse feita post mortem" (BARROSO apud AUSTEN, 2011, p. 12).

Entretanto, Jane Austen não foi uma escritora-fantasma, ou ghostwriter, cujo nome não consta na ficha catalográfica como autor porque se trata de escrita por meio de contrato ou encomenda a ser creditada a outrem. A autora vendeu seus romances, mas esses não lhe foram creditados nas primeiras edições, pelas restrições do patriarcal mercado editorial inglês do século XIX. Ademais, apesar de não gozar de seu nome estampado na capa dos romances, Austen era reconhecida em seu meio social mais íntimo como autora de seus romances. Trata-se, pois, do caso de uma zombie-writer, ou escritora-zumbi (KOBS, 2014), e não de uma ghostwriter.

Outra visão sobre a autoria em Jane Austen pode ser estabelecida a partir desse ponto: partindo da premissa de que Austen preferiu por conta própria não figurar como "autora" de seus livros, pois sabia que uma mulher exercendo tal profissão não era vista com bons olhos pela sociedade inglesa oitocentista, o uso da palavra author em suas obras poderia ser um sinal de resistência por parte da escritora, a fim de não adotar um pseudônimo, como seria comum mais tarde no século XIX. Exemplos célebres de tal prática viriam a ser as irmãs Brontë - Anne, 
Charlotte e Emily -, que publicaram, respectivamente, sob os pseudônimos de Acton Bell, Currer Bell e Ellis Bell; e Mary Ann Evans, a qual adotou o pseudônimo de George Eliot.

Austen poderia ter usado esse mesmo expediente, porém preferiu seguir outro caminho e não ficar sob o codinome de um homem. Em vez disso, subverteu os paradigmas da autoria da época, colocando-se como inominável - e não mencionável - author.

\section{A tecnologia da escrita e sua influência na autoria de Pride and Prejudice and Zombies}

A partir da análise da seção anterior sobre a publicação dos romances austenianos, poderíamos iniciar esta pontuando que falar de autoria em Jane Austen é falar desde sempre de ausência, de um discurso que, já em suas primeiras edições, não pôde ser atribuído a uma voz autoral empírica, a qual, como não mencionável, ensejaria no século XXI a existência de uma obra-zumbi. Assim, em Pride and Prejudice and Zombies, Jane Austen se confirmaria como presença da ausência, que se manifesta apenas através da tecnologia da escrita.

Nesse romance mashup, enquanto Grahame-Smith exerce uma força primária sobre o texto final, a de Jane Austen é secundária e menos nítida, pois a escritora não comparece sincronicamente enquanto sujeito empírico no ato de criação. A interação acontece entre o locutor (Austen) e seu interlocutor (Grahame-Smith), que se torna co-locutor de Austen na medida em que se reapropria da emissão do discurso da autora. Nesse sentido, há uma "interação verbal", mas não uma "interação pessoal" entre esses sujeitos do discurso, mediada por diferentes recursos técnicos de escrita.

Pride and Prejudice foi escrito em uma época na qual a tecnologia digital que conhecemos hoje era inexistente. Para escrever seu romance, Jane Austen teve que usar os dispositivos de escrita de sua época, fazendo uso de caneta de pena, tinta, papel e mata-borrão, ao passo que Seth Grahame-Smith se reapropriou do texto da autora por meio de um editor digital de textos com ferramentas que possibilitaram, de forma rápida, atividades de recortar, copiar e colar.

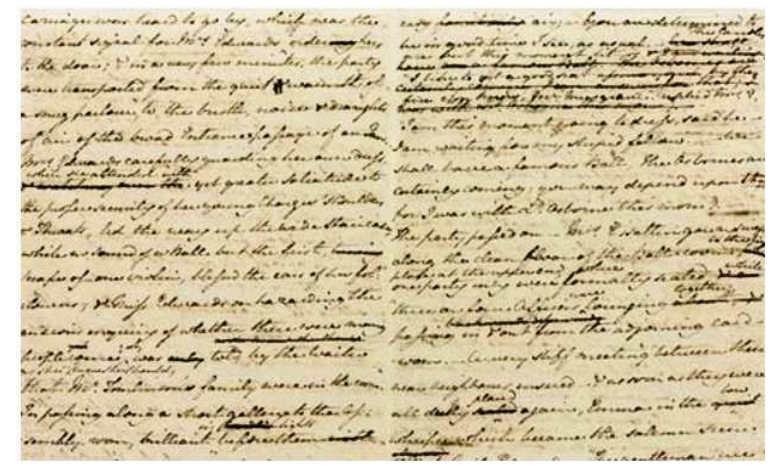

Figura 4. Manuscrito de The Watsons com amostra da escrita de Jane Austen. Fonte: http://www.theguardian.com/books/2011/jul/14/jane-austen-manuscript-the-watsons. Acesso em 08 ago 2015. 
Quando se utiliza de papel, tinta e caneta de pena, os erros inerentes ao processo de escrita não podem simplesmente ser apagados ou deletados. Na Figura 4, observa-se que em algumas partes do manuscrito há traços fortes, como se a autora quisesse apagar o que havia escrito. $\mathrm{Na}$ ausência de dispositivos de supressão do erro gráfico, ao autor de sua época não restava alternativa senão indicar, com marcas à tinta, trechos a serem eliminados na próxima versão de prova.

Por conseguinte, escrever à tinta requer maior cuidado na feitura do texto, pois pressupõe maior acompanhamento de cada palavra ou ideia presente nele. Isso se deve ao fato de que a caneta de pena implica uma reduzida velocidade da escrita, a que se soma o que há de pictórico na escrita cursiva. Segundo tal perspectiva, esses dispositivos de escrita convidam a uma contemplação do texto enquanto imagem que se depõe no papel em sucessivos rascunhos e ensaios, no árduo processo de reescrita do texto que se supõe final.

O emprego de uma técnica de escrita como a que Austen usou para escrever seu texto, o qual compõe oitenta e cinco por cento da massa final de Pride and Prejudice and Zombies, levou, pois, tempo. Pride and Prejudice foi escrito pela primeira vez entre outubro de 1796 e agosto de 1797 (AUSTEN-LEIGH, 2014) e passou por extenuante revisão mais de dez anos depois. Usando a tecnologia de escrita de seu tempo, Jane Austen levou quase um ano para escrever a primeira parte do que viria a ser no século XXI a obra-zumbi e aguardou para a primeira revisão quase um terço do seu tempo de vida.

Por outro lado, o uso do computador na produção de Pride and Prejudice and Zombies (KELLOGG, 2009) garantiu a Grahame-Smith maior velocidade na escrita do texto, demandada sobretudo pelo caráter de encomenda da obra pela editora. ${ }^{12}$ Ademais, composto no computador, Pride and Prejudice and Zombies não tem sua gênese historicizada por sucessivas versões e rascunhos, pois o editor de texto inviabiliza esse processo. No texto digital, os eventuais erros do processo de escrita não ficam visíveis, pois as versões podem facilmente ser salvas umas sobre as outras no mesmo arquivo, o que faz "sumirem" as versões anteriores. Contudo, diferentemente de outros romances contemporâneos também escritos em editores de texto digitais, em Pride and Prejudice and Zombies o processo de escrita pode ser dito ainda mais rápido. Afinal, após Grahame-Smith ter realizado a leitura de Pride and Prejudice e demarcado aquilo que julgava dever ser retirado, o autor apenas precisou transcrever o texto para outro arquivo e inserir as cenas com os zumbis.

Curioso é pensar que, nessa dinâmica, as impressões digitais de Grahame-Smith ficaram sobre seu computador, não sobre o texto. Fora as teclas da máquina, as digitais do autor ficaram apenas nas páginas de Pride and Prejudice, enquanto ele efetuava a leitura do romance para destacar os excertos a serem extirpados. Por outro lado, as impressões digitais de Austen estão em toda a parte do manuscrito de seu romance, confirmando a presença indelével da autora, ainda que seu nome não conste nas primeiras edições.

A esse respeito, vale lembrar a postulação de Roger Chartier (1998), para quem a tecnologia digital possibilitou um afastamento entre o texto e quem o escreve: 
O texto eletrônico torna possível uma relação muito mais distanciada, não corporal. O mesmo processo ocorre com quem escreve. Aquele que escreve na era da pena [...] produz uma grafia ligada diretamente aos gestos corporais. Com o computador, a mediação do teclado, que já existia com a máquina de escrever, mas que se amplia, instaura um afastamento entre o autor e seu texto (CHARTIER, 1998, p. 16).

Assim, em paradoxal jogo de reflexos no ato de escrita de Pride and Prejudice and Zombies, podemos ver a presença de Grahame-Smith, de nome estampado na capa, mas sem o rastro de seu corpo sobre o papel. Por sua vez, a escritora que só foi chamada de "an author" em seus romances comparece aí com os índices, pegadas das mãos, marcando com seu corpo o texto que depois dará origem ao romance-mashup. Presença e ausência, vida e morte: esse é o jogo de todo zumbi.

$\mathrm{O}$ entendimento de que Pride and Prejudice and Zombies é uma literatura de segunda mão é corroborado pelas tecnologias da escrita empregadas em sua composição, pois o uso do computador tira de quem está escrevendo a chance de o peso da mão marcar o papel, em irrepetível encontro entre corpo anatômico e corpo textual. Grahame-Smith precisou somente riscar no arquivo de texto de Pride and Prejudice aquilo que não usaria; depois, apenas copiou e colou o restante da massa textual em outro documento para inserir-lhe pequenas modificações e formar a obra-zumbi. Já a letra de Austen torna seu texto único e se constitui como índice de um laborioso trabalho de escrita, revestindo-o da aura de que tanto falara Walter Benjamin (1994).

O entendimento de que há duas culturas (a digital e a impressa) de escrita que convergem na confecção do romance sugere que Pride and Prejudice and Zombies conta a história da evolução do conceito de autoria, através da evolução do suporte do texto: do manuscrito ao livro impresso em Austen e do livro impresso ao arquivo digital em Grahame-Smith. Assim, podemos inferir que a fusão da autoria na capa do romance, explicitamente creditado à romancista inglesa oitocentista e ao ficcionista norte-americano contemporâneo, conta a história da imbricação de suportes que ensejou a obra.

Ainda no que tange aos suportes que confluem para a redação de Pride and Prejudice and Zombies, a contracapa do livro merece ser analisada. Em um primeiro olhar, a justaposição dos nomes de ambos os autores na capa do romance daria aos dois o mesmo status. Contudo, uma leitura mais detalhada do texto da contracapa parece suscitar outra interpretação dessa autoria compartilhada.

JANE AUSTEN é autora de Razão e Sensibilidade, Persuasão, Mansfield Park entre outras obras primas da Literatura Inglesa. SETH GRAHAMESMITH uma vez fez um curso de Literatura Inglesa ${ }^{13}$ (AUSTEN; GRAHAME-SMITH, 2009, n.p., tradução nossa).

Aqui, Jane Austen é descrita como a autora de famosas obras da literatura inglesa canônica. Tal prestígio pode impulsionar as vendas do romance, segundo os procedimentos de marketing caros ao mercado editorial. Por outro lado, 
Grahame-Smith é jocosamente descrito de maneira lacunar na contracapa, como "alguém que uma vez fez um curso de Literatura Inglesa", ainda que seja também roteirista, produtor de séries e filmes e autor de best sellers como Abraham Lincoln, Vampire Hunter (2010) e How to Survive a Horror Movie: All the Skills to Dodge the Kills (2007). A contraposição que a retórica do parágrafo acentua na contracapa do livro, entre a consagrada autora inglesa e alguém que tem apenas conhecimento superficial da literatura inglesa, além de dispositivo publicitário que chama a atenção do leitor para a inusitada obra, carrega um julgamento implícito da autoria: Austen seria a mente criadora do texto e Grahame-Smith uma espécie de mente transformadora.

A esse respeito, vale lembrar que Chartier (1998) define autor como aquele "cujo nome próprio dá identidade e autoridade ao texto" (CHARTIER, 1998, p. 32), ao passo que o escritor seria aquele que "escreve alguma coisa" (CHARTIER, 1998, p. 32). No bojo da mesma discussão, Chartier toma o autor como "aquele que publicou obras impressas" (CHARTIER, 1998, p. 32), enquanto o escritor seria aquele que "escreveu um texto que permanece manuscrito, sem circulação" (CHARTIER, 1998, p.32).

Se analisarmos a autoria em Jane Austen à luz dos conceitos de Chartier (1998), diríamos, então, que esta foi autora de seus seis romances enquanto eles estavam em formato de manuscrito, mas, quando passaram a livros, ela perdeu a autoria, só a recuperando alguns anos após sua morte, quando finalmente seu nome passou a estampar as capas dessas obras. Trata-se, então, de autora em primeira instância, pois é seu nome que dá autoridade e identidade ao texto. Já em Seth Grahame-Smith, a autoria acontece em segundo grau, pois ele se apossa de um romance consagrado e imprime sua marca através da inserção dos zumbis; assim, sua autoria é na verdade coautoria com Austen.

Para entendermos melhor como, em termos editoriais, se dá essa autoria zumbi, compartilhada entre uma escritora morta e um vivo, analisemos a ficha catalográfica (Figura 5) de Pride and Prejudice and Zombies. Na parte superior da ficha, aparece a expressão "Copyright @ 2009 by Quirk Productions, Inc.", que indica que os direitos autorais do romance pertencem exclusivamente à corporação Quirk Productions e qualquer uso do romance requer pedido de autorização a essa editora, cujo nome e endereço são apresentados na parte inferior da ficha. 


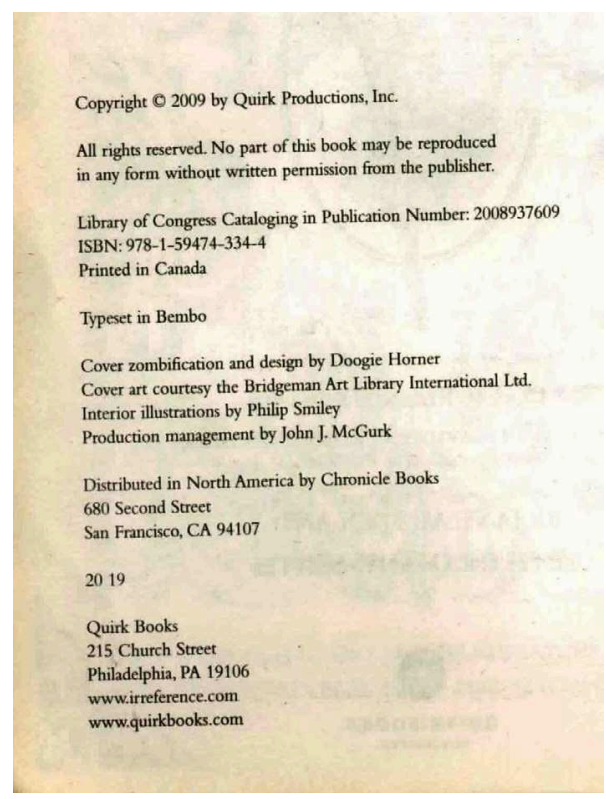

Figura 5. Ficha catalográfica de Pride and Prejudice and Zombies (AUSTEN; GRAHAMESMITH, 2009, p. 4).

Deter os direitos autorais de um romance significa que ele é de propriedade intelectual da editora e apenas a ela cabe explorar o romance e lucrar com sua publicação. Logo abaixo, aparece outra expressão que melhor explana a noção de propriedade literária sobre Pride and Prejudice and Zombies: “Todos os direitos estão reservados. Nenhuma parte deste livro pode ser reproduzida sem permissão por escrito da editora" (AUSTEN; GRAHAME-SMITH, 2009, n.p).

A ficha catalográfica notifica ainda que Pride and Prejudice and Zombies foi impresso no Canadá com fonte Bembo; que a capa do romance foi zumbificada por Doogie Hurner; que a imagem original foi uma cortesia da Bridgeman Art Library International Ltd.; e que as ilustrações ao longo do romance foram produzidas por Philip Smiley.

Porém, o ponto central da ficha está na indefinição do autor: não há na ficha catalográfica dessa versão os nomes de Jane Austen e Seth Grahame-Smith, que só constam na capa do romance. Tal dinâmica torna-se mais complexa quando relembramos que a ideia de mesclar o romance clássico com um texto contemporâneo partira de encomenda pelo editor da Quirk Books, Jason Rekulak (AUSTEN; GRAHAME-SMITH, 2009), o que introduz um terceiro elemento - um mandatário - na dinâmica de coautoria do romance. Considerando o fato de a Quirk Books ter se especializado na produção de romances-mashup, resta ainda mais evidente a associação entre mercantilização e autoria que reproduziu, nos demais mashups publicados pela editora, ${ }^{14} \mathrm{o}$ modelo de hibridação textual de Pride and Prejudice and Zombies.

Nesse contexto, a discussão da autoria envolve não necessariamente quem escreveu o livro, mas sim quem vai usufruir dos direitos autorais do romance: no contrato entre Grahame-Smith e a Quirk Books, apenas estes obtiveram lucro com a publicação do romance. Os familiares vivos de Austen não obtiveram nenhum benefício financeiro com a publicação de Pride and Prejudice and Zombies, 
uma vez que o romance já está em domínio público, o que inviabiliza qualquer disputa judicial.

A existência desse tipo de associação entre um autor vivo e uma editora é o que faz com que o texto de um autor morto, reativado pelo mashup, circule com nova propulsão de mercado. Assim, ainda à luz de Chartier (1998), Pride and Prejudice and Zombies possui uma autoria coletiva, pois pertence tanto a quem escreveu a obra - Austen e Grahame-Smith - quanto a todos os outros que participaram de seu processo de concepção.

Já a ficha catalográfica da tradução para o português, Orgulho e Preconceito e Zumbis (figura 6), publicado no Brasil pela Editora Intrínseca, apresenta os nomes dos coautores Austen e Grahame-Smith, o que pode sugerir um diferente entendimento da autoria no romance mashup.

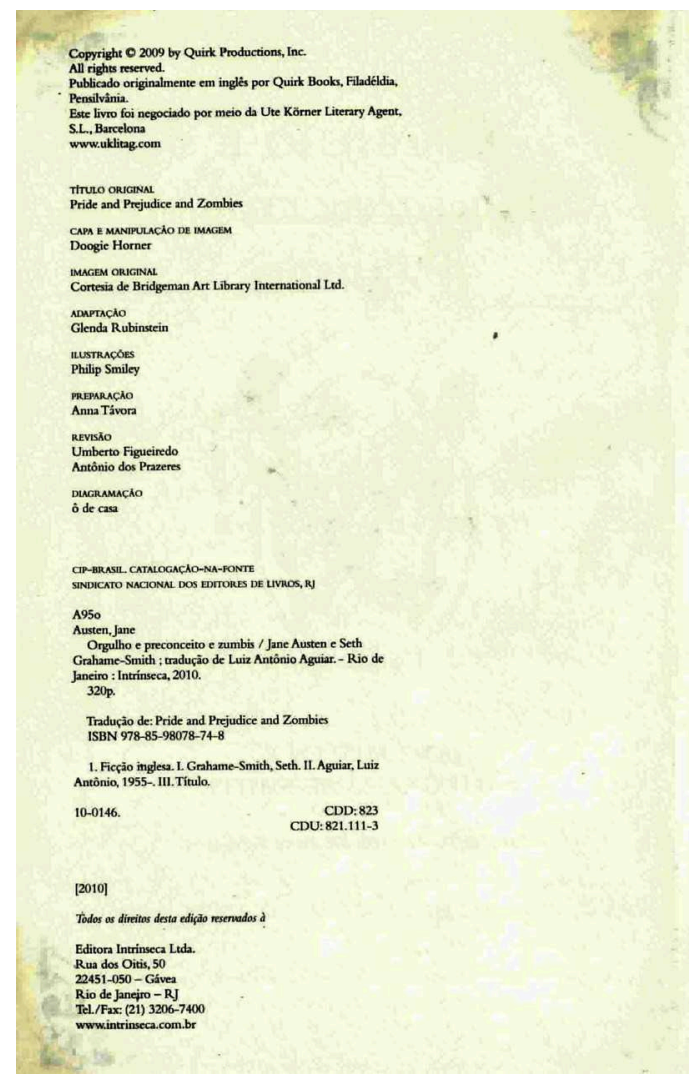

Figura 6. Ficha catalográfica de Orgulho e Preconceito e Zumbis (versão brasileira) (AUSTEN; GRAHAME-SMITH, 2010).

O que se observa na ficha norte-americana é que a ideia de autoria se liga à noção de propriedade por parte da editora, garantindo apenas ao detentor dos direitos autorais um nome na ficha catalográfica. Por outro lado, na versão brasileira, a despeito da venda ou da cessão de direitos autorais, há um modelo que serve como padrão, explicitando o nome dos escritores como autores do texto. Assim, se na ficha norte-americana quem aparece é um autor-proprietário (a Quirk Books), na versão traduzida no Brasil temos o nome do autor-criador (Jane Austen) e do autor-leitor (Grahame-Smith). 
Tal tripartição, ora mais explícita ora menos explícita nas fichas catalográficas, sugere os vários processos executados ao longo da produção de Pride and Prejudice and Zombies: desde a sua inscrição no papel, com Jane Austen, passando pela adaptação, com Grahame-Smith, e chegando à sua publicação (por encomenda), pela editora Quirk Books. Corpo textual que ora se retalha, ora se enxerta, tal qual os zumbis recompostos de fragmentos de corpos, Pride and Prejudice and Zombies traz de volta à vida, por uma autoria morta-viva, textualidades austenianas sob novas perspectivas, que aqui se optou por analisar à luz da imagem do zumbi.

\section{Considerações finais}

Neste estudo, buscamos discutir o fenômeno da autoria-zumbi em Pride and Prejudice e Zombies partindo da imagem desse morto-vivo e da dinâmica autoral de ausência e presença, morte e vida, inerente à primeira publicação dos canônicos romances de Jane Austen. Morta há quase dois séculos, Austen assim ressurge no mercado editorial como best seller, a reboque das jogadas de marketing que se beneficiam da onda zumbi na cultura pop.

Por sua vez, o zumbi, como um monstro que se mostra, dando a ver a si e ao contexto que o gerou, faz de Pride and Prejudice and Zombies um morto-vivo literário que nos convida a ler e a pensar sobre a literatura de nosso tempo, revelando-nos novas possibilidades de construção de instâncias autorais, ou mesmo novas maneiras de reler a dinâmica autoral de romances canônicos, tais quais os de Jane Austen. Como mote da leitura aqui ensejada, o zumbi adicionado ao enredo de Pride and Prejudice metaforiza o processo de autoria colaborativa do romance, na medida em que se confirma a instância autoral de Pride and Prejudice and Zombies como morta-viva, com Jane Austen, a "autora morta", e Seth Grahame-Smith, o "autor vivo".

Notas

1. Texto original: "texts composed by combining portions from several texts".

2. Texto original: "An expanded edition of the beloved Jane Austen novel featuring all-new scenes of bone-crunching zombie mayhem".

3. Texto original: "Delightful comedy of manners with plenty of civilized sparring between two young lovers - and even more violent sparring on the blood-soaked battlefield".

4. Ainda que um conjunto significativo de críticas possa ser feito à imagem reducionista de Jane Austen construída por Austen-Leigh (2014), sobretudo em termos de estereótipos de gênero, são fundamentais ao argumento desenvolvido neste artigo os dados que o sobrinho da autora apresenta sobre o processo de escrita e publicação dos romances austenianos.

5. Optou-se aqui por utilizar, na tradução, uma marca tipográfica que desidentifica o gênero, uma vez que, na língua inglesa, a expressão "the author" não carrega gênero gramatical como no português. 
6. O romance foi originalmente publicado em três volumes em 1813, sendo aqui apresentada para fins de análise a folha de rosto do primeiro volume.

7. Tradução nossa: "Dx autorx de Razão e Sensibilidade".

8. Texto original: "Her voice was extremely sweet. She delivered herself with fluency and precision. Indeed she was formed for elegant and rational society, excelling in conversation as much as in composition. In the present age it is hazardous to mention such accomplishments".

9. Tradução nossa: "Dx autorx de Orgulho e Preconceito e Mansfield Park etc".

10. Texto original: "The following pages are the production of a pen which has already contributed in no small degree to the entertainment of the public. And when the public, which has not been insensible to the merits of "Sense and Sensibility," "Pride and Prejudice," "Mansfield Park," and "Emma," shall be informed that the hand which guided that pen is now mouldering in the grave, perhaps a brief account of Jane Austen will be read with a kindlier sentiment than simple curiosity".

11. Tradução nossa: "Nossa autora, provavelmente, teria sido inferior a poucos em tais habilidades, se não tivesse sido superior a muitos em coisas maiores".

12. Segundo Seth Grahame-Smith, a ideia de mesclar um romance clássico com a literatura contemporânea partira do editor da Quirk Books, Jason Rekulak, que lhe dera o título do romance, com um prazo curto, pedindo apenas que se inserissem zumbis no texto austeniano (HUMBERG, 2005, n.p.).

13. Texto original: "JANE AUSTEN is the author of Sense and Sensibility, Persuasion, Mansfield Park and other masterpieces of English literature. SETH GRAHAMESMITH once took a class in English literature".

14. Pela mesma editora, foram publicados Android Karenina, de Leo Tolstói e Ben H. Winters; Romeo and Juliet and Vampires, de William Shakespeare e Claudia Gabel; Little Vampire Women, de Louisa May Alcott e Lynn Messina e The Meawmorphosis, de Franz Kafka e Cook Coleridge. Os dois primeiros foram lançados em 2010, enquanto os outros entraram para o mercado literário apenas em 2011.

\section{Referências}

AUSTEN-LEIGH, James Edward. Uma Memória de Jane Austen. Tradução de José Loureiro e Stephanie Savalla. Domingos Martins: Pedrazul, 2014.

AUSTEN, Jane. Persuasão. Tradução de Celina Portocarrero. Porto Alegre: L \& PM, 2011.

AUSTEN, Jane; GRAHAME-SMITH, Seth. Orgulho e Preconceito e Zumbis. Tradução de Luiz Antônio Aguiar. Rio de Janeiro: Intrínseca, 2010. Título original: Pride and Prejudice and Zombies.

Pride and Prejudice and Zombies. Philadelphia: Quirk Books, 2009.

BARTHES, Roland. Aula. Tradução de Leyla Perrone-Moisés. São Paulo: Cultrix, 1992.

A morte do autor. O Rumor da Língua. Tradução de Mario Laranjeira. São Paulo: Martins Fontes, 2004.

BENJAMIN, Walter. A obra de arte na era da reprodutibilidade técnica. Magia e técnica, arte e política: ensaios sobre literatura e história da cultura. Tradução de Sérgio Paulo Rouanet. São Paulo: Brasiliense, 1994.

CHARTIER, Roger. A aventura do livro: do leitor ao navegador: conversações com Jean Lebrun. Tradução de Reginaldo Carmello Corrêa de Moraes. São Paulo: Imprensa Oficial do Estado de São Paulo: Editora UNESP, 1998. 
ECO, Umberto. Obra aberta. Tradução de Giovanni Cutolo. São Paulo: Perspectiva, 1991.

GOMES, Anderson Soares. (De)composições do corpo físico e social: a emergência do zumbi na ficção norte-americana contemporânea. Revista Gragoatá, UFF Niterói, v. 18, n. 35, pp. 97-116, $2^{\circ}$ sem/2013.

HUMBERG, Mário Ernesto. "O ghostwriter e a ética na comunicação". Gazeta Mercantil, 03 de mai. 2005. Disponível em: <http://www.sinprorp.org.br/ clipping/2005/132.htm>. Acesso em 06 nov 2015.

JESUS, Ivoneide Soares dos Santos de; PEREIRA, Vinícius Carvalho. Instância autoral morta-viva em Orgulho e Preconceito e Zumbis. Desenredo (PPGL/UPF), v. 11, n. 1, pp. 155-169, 2015.

KELLOGG, Carolyn. Pride and Prejudice and Zombies by Seth Grahame-Smith. Los Angeles Times, 04 de abr. 2009. Disponível em: <http://www.latimes.com/ entertainment/la-et-zombies4-2009apr04-story.html>. Acesso em $22 \mathrm{dez} 2014$.

KOBS, Veronica Daniel. Brás Cubas, o autor-zumbi de Memórias Desmortas. Scripta Uniandrade, v. 12, n. 2, jul-dez, 2014.

MORLAND'S. Circulating Library. Biographical Notice of the Author. Disponível em: $<$ http://www.mollands.net/etexts/northangerabbey/bio.html>. Acesso em 20 nov 2015.

MURPHY, Jacob. Remix Culture and the Literary Mashup. Alluvium, Birbeck, Universidade de Londres, v. 2, n. 2 n. pag, 25 de mar. de 2013. Disponível em: $<$ http://dx.doi.org/10.7766/alluvium.v2.2.02>. Acesso em 04 set 2015.

RUSSELL, Jamie. Zumbis: O Livro dos Mortos. Tradução de Érico Assis e Marcelo Andreani de Almeida. São Paulo: Leya Cult, 2010.

SCHNEIDER, Matt. Plagiarism as Authorship: the Literary Mashup. Edmonton: University of Alberta, 2009.

TAKAHASHI, Deborah. Pride and Prejudice and Zombies by Jane Austen, Seth Grahame-Smith, Tony Lee, and Cliff Richards. Pasadena, 17 de mai. 2011. Disponível em: <http://ladykazumi.blogspot.com.br/2011/05/pride-andprejudice-and-zombies-by-jane.html>. Acesso em 06 jun 2015.

Recebido em: 03/11/2017

Aceito em: 27/03/2018 